
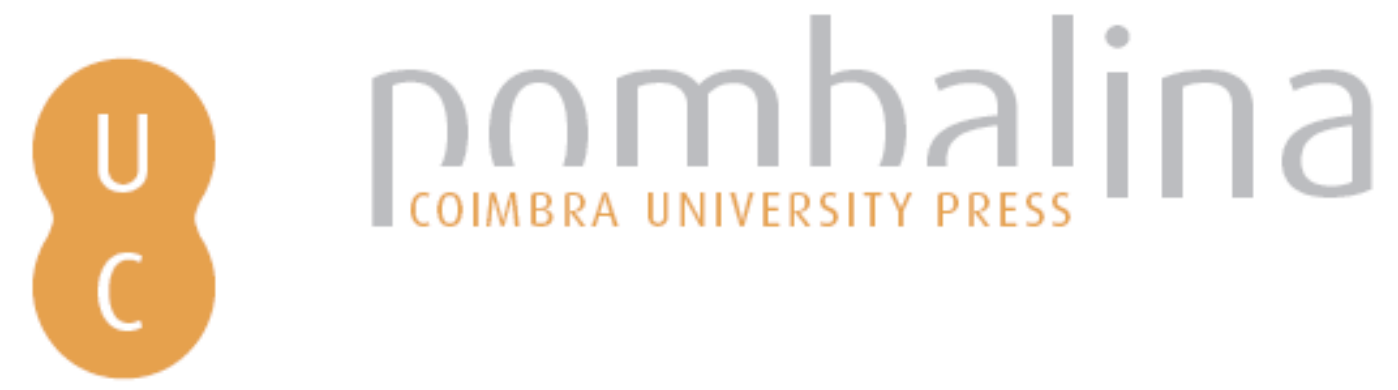

\title{
Edipo en Latinoamérica. Todo un show. Un acercamiento a Edipo rey y su señora mamacita de Peky Andino Moscoso
}

\author{
Autor(es): $\quad$ Ferrari, Silvana Soledad \\ Publicado por: Imprensa da Universidade de Coimbra \\ URL \\ persistente: URI:http://hdl.handle.net/10316.2/42961 \\ DOI: $\quad$ DOI:https://doi.org/10.14195/978-989-26-1439-7_18 \\ Accessed : $\quad$ 26-Apr-2023 09:03:38
}

A navegação consulta e descarregamento dos títulos inseridos nas Bibliotecas Digitais UC Digitalis, UC Pombalina e UC Impactum, pressupõem a aceitação plena e sem reservas dos Termos e Condições de Uso destas Bibliotecas Digitais, disponíveis em https://digitalis.uc.pt/pt-pt/termos.

Conforme exposto nos referidos Termos e Condições de Uso, o descarregamento de títulos de acesso restrito requer uma licença válida de autorização devendo o utilizador aceder ao(s) documento(s) a partir de um endereço de IP da instituição detentora da supramencionada licença.

Ao utilizador é apenas permitido o descarregamento para uso pessoal, pelo que o emprego do(s) título(s) descarregado(s) para outro fim, designadamente comercial, carece de autorização do respetivo autor ou editor da obra.

Na medida em que todas as obras da UC Digitalis se encontram protegidas pelo Código do Direito de Autor e Direitos Conexos e demais legislação aplicável, toda a cópia, parcial ou total, deste documento, nos casos em que é legalmente admitida, deverá conter ou fazer-se acompanhar por este aviso.

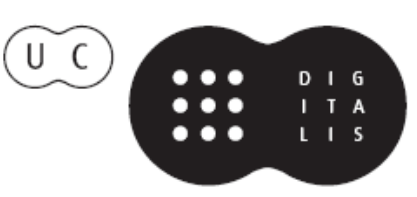




\section{Pervivencia del mundo clásico en la literatura:}

\section{tradición y relecturas}

\section{Aldo Rubén Pricco, Stella Maris Moro (coords.)}

IMPRENSA DA UNIVERSIDADE DE COIMBRA 


\title{
Edipo en Latinoamérica. Todo un Show. Un acercamiento a Edipo Rey y su señora mamacita de Peky Andino Moscoso (Oedipus in Latinoamerica. A show. An approach of Peky Andino Moscoso' Edipo rey y su señora mamacita)
}

\author{
Silvana Soledad FerRari (silsolferrari@hotmail.com)
}

UADER

\begin{abstract}
Resumen - El presente trabajo pretende realizar un recorrido, desde el campo literario, de la obra teatral Edipo rey y su señora mamacita (presidente que se casó con su madre) (1998) de Peky Andino Moscoso (Ecuador, 1962). El objetivo de éste es mostrar cómo, a través de las relaciones que existen con la obra de Sófocles y los discursos sociales contemporáneos -intertextual (Genette: 1962; Kristeva: 1968) e interdiscursiva (Angenot: 1984) - y la utilización de la parodia, la ironía y el humor ácido para la reconstrucción del mito clásico, se intenta realizar una reflexión históricosocial de Ecuador y del mundo contemporáneo.

Palabras Clave: Edipo Rey, intertextualidad, interdiscursividad, teatro latinoamericano, Andino Moscoso.
\end{abstract}

Aвstract - The following article aims to present a review from the literary field of the 1998 play by Peky Andino Moscoso (Ecuador, 1962): Edipo rey y su señora mamacita (presidente que se casó con su madre). It tries to show how, by means of the existing relationship between Sophocles' work and contemporary social discourses, —intertextual (Genette; 1962; Kristeva: 1968) and interdiscursive (Angenot: 1964) - as well as the use of parody, irony and caustic humour to rebuild the classic myth, it expects to make a socio-historical appraisal of Ecuador and the contemporary world.

Keywords: Oedipus the King, intertextuality, interdiscursivity, Latin-American theatre, Andino Moscoso.

Los reyes nacemos para perpetuar las desgracias del poder y para dar de comer a los paparazzis. Peky Andino Moscoso

Este trabajo pretende realizar un análisis del texto dramático Edipo rey y su señora mamacita (presidente que se casó con su madre) (1998) del autor y director ecuatoriano Peky Andino Moscoso (n. 1962). En este recorrido se intenta desentrañar cómo a partir de las relaciones que se pueden encontrar en la obra, no solo con su hipotexto Edipo Rey de Sófocles; sino también con los distintos discursos sociales, se realiza una reflexión histórico-social del mundo contemporáneo.

Peky Andino Moscoso califica sus obras como bombas que planta sobre 
el escenario ${ }^{1}$, que pretenden ser más que una simple puesta en escena, ya que tienen que explotarle al espectador. Para construirlas utiliza diferentes discursos y es esto lo que se intenta analizar aquí. Por ello se deben tener en cuenta dos conceptos teóricos: por un lado, intertextualidad que según Julia Kristeva manifiesta que la escritura es considerada “(...) como lectura del corpus literario anterior, el texto como absorción y réplica a otro texto"2. Edipo rey y su señora mamacita, retoma la tragedia de Sófocles y la mitología griega para parodiarlas a través de la reescritura.

Pero la obra no se agota en esto, sino que también entrelaza discursos sociales y es por ello que se introduce el segundo concepto: interdiscursividad, definido por Angenot como “(...) interacción e influencias axiomáticas de discursos continuos"3. Desde una concepción de interacción sincrónica, va a entender un tex to como "(...) una costura, un zurcido de 'collages' heterogéneos de fragmentos erráticos del discurso social, integrados a un telos particular"4.

Es a partir de esta idea que se considera a la obra de Andino Moscoso como interdiscursiva, ya que no solamente está presente en ella el discurso literario, sino que también trabaja, como casi toda la obra del dramaturgo, temáticas sociales actuales; en este caso la política y la influencia de los medios masivos de comunicación. Por esto, se entraman en la escritura programas televisivos, el discurso publicitario, canciones, creencias y aspectos históricos sociales.

Las estrategias que utiliza el autor para montar el texto dramático son la parodia, la ironía y el humor ácido que le permiten reconstruir a su antojo el mito clásico. Los personajes, Edipo y Yocasta, son sometidos al escarnio público a través de la televisión porque no desean cumplir los designios del destino.

La obra está situada temporal y espacialmente, como leemos en el prólogo "Año (1997), sala de ejecuciones del hospital de Tebas" ${ }_{5}$. Por lo tanto, ya se está marcando la diferencia con el hipotexto ${ }^{6}$, hay un cambio de espacio y tiempo, se trae al presente la tragedia griega, pero también se puede considerar que Andino Moscoso continúa la obra de Sófocles o, para decirlo de otro modo, pretende cambiar su final. Ya que la trágica relación entre Edipo y Yocasta, es un hecho público: "La madre que tuvo hijos, y el hijo que tuvo hermanos en su madre fueron encerrados en la Sala de Emergencias del Hospital de Tebas: la profecía se ha cumplido"7; pero la diferencia fundamental es la rebelión que los protagonistas van a manifestar

\footnotetext{
${ }^{1}$ Hartwig et al. 2008: 92.

${ }^{2}$ Kristeva 1969: 195.

${ }^{3}$ Angenot 1984: 74.

${ }^{4}$ Angenot 1984: 69.

${ }^{5}$ Geirola 2010: 501.

${ }^{6}$ Teniendo en cuenta la definición de hipertextualidad, acuñada por Gerard Genette 1989.

${ }^{7}$ Geirola 2010: 501.
} 
sobre cumplir con su destino, destinos que ellos ya conocen: “(...) Si paramos la ejecución de mi aorta y de tus ojos, ¿qué pasaría?”, le pregunta Yocasta a su marido/hijo. Ante esta negativa el presidente y su esposa son sometidos al show de la televisión.

Es posible seguir encontrando diferencias y semejanzas con la obra clásica Griega. El segundo acto, de los once con los que cuenta, sin incluir el prólogo, se titula “¿Quién eres Yocasta? ¿Quién eres Edipo?”, los personajes encerrados en la celda del hospital se interrogan, para intentar desentrañar la verdad. Intentan convencerse de su realidad, sin dejar de lado el humor ácido: "Yocasta: (...) ¿cómo deberé llamarte, Edipo? ¿Mi Rey, mi marido, o hijo mío? / Edipo: Llámame con el nombre que nunca me has llamado, llámame... enfermero" ${ }^{\text {. Este diálogo }}$ remite a la tragedia de Sófocles, ya que en ella Yocasta manifiesta: "(...) ¡Ay! ¡Ay, desgraciado! Este es el único nombre que puedo llamarte, y nunca te llamaré de otro modo" 10 .

Aquí también se menciona a uno de los personajes clave de la tragedia griega, Layo: “(...) un flaco travesti (...) que sedujo al hijo del rey Pélope quien lo maldijo a que su descendencia se alimentara con su sangre"11. Sigue presente el vaticinio del oráculo, pero la figura del Rey Layo, es ridiculizada. Su muerte también sufre modificaciones: el monarca acostumbraba seducir jóvenes en los cruces de camino y es asesinado por un experto en crucigramas con un bisturí. Mientras que Sófocles explica su muerte de la siguiente manera: “(...) le dieron muerte, según se ha dicho, unos salteadores extranjeros en una encrucijada de tres caminos (...)"12.

La Esfinge que Hera había enviado como castigo a la ciudad de Tebas, en la obra de Andino Moscoso es un profesor de Anatomía, que atormentaba al pueblo con el acertijo "del animal al que al amanecer le colocaban un reloj en el pecho, un laúd al mediodía, y al anochecer un corazón que no le servía para nada” ${ }^{13}$. La respuesta al igual que en la adivinanza de la Esfinge es el hombre. Pero en este caso, se puede reflexionar sobre el contenido de la misma: al envejecer, cuando la vida está llegando a su fin, el hombre adquiere un corazón, pero ya es tarde.

En la obra además son mencionados los hijos del matrimonio y Creonte, quien es uno de los personajes, que al igual que en la tragedia griega, pretende mejorar la situación del país. Con esto, se permite ejemplificar la relación hipertextual ${ }^{14}$ de la obra con la tragedia de Sófocles y con la mitología, no solo la

\footnotetext{
${ }^{8}$ Geirola 2010: 504.

${ }^{9}$ Geirola 2010: 503.

${ }^{10}$ S., O.T. 1072-1073.

${ }^{11}$ Geirola 2010: 503.

${ }^{12}$ S., O. T. 713-714.

${ }^{13}$ Geirola 2010: 503.

${ }^{14}$ Genette 1989.
} 
relacionada con Edipo, ya que aparecen también otros personajes como Orestes o Agamenón.

En Edipo Rey se dirimen los sucesos que aquejan a Tebas fuera de Palacio, frente a los ciudadanos, los tiempos han cambiado y en la obra de Andino Moscoso todo sucede en un show televisivo, donde van a transitar diferentes personajes y distintos formatos; pero sobre todo donde el pueblo está del otro lado, formando parte del suceso.

Es a partir de esto que se puede pensar en diferentes relaciones interdiscursivas. El primer acto, "Payaso tv", dialoga directamente con el discurso periodístico, tres payasos presentan las noticias del día. Obviamente la más importante es el descubriendo de la situación del presidente y la primera dama; pero también encontramos, por ejemplo: "Los funcionarios del reino escapan a Corinto con los maletines de Pandora: la burocracia ha cumplido"15. Esta última expresión se repite en todas las informaciones, los vaticinios se van cumpliendo, excepto el que más les interesa: “'Si todos han cumplido, por qué no has de cumplir tú, reina madre, con tu deber de apretarte el cuello? ¿Por qué, rey hijo, no has de pagar con tus ojos las deudas imprescriptibles del destino?"

Se debe agregar, que los payasos mencionan a Tiresias, como un periodista que muestra en televisión “(...) mujeres peces y niños cobras (...)” ${ }^{17}$. Se puede pensar que el adivino ciego, que todo lo sabe, en la era de la comunicación es un periodista de investigación que se encarga de mostrar las verdades del mundo o un amarillista en busca de rating.

El cuarto acto, se titula "El show de las gorgonas", típico talk show, donde el público, calificado como idiota, en el piso o desde su casa puede realizarle preguntas a los invitados. Obviamente el tema a tratar será "Hijos que se casaron con sus madres". Con este simple apelativo con que se designa al espectador encontramos un guiño de desprecio hacia los productos televisivos y la incapacidad de discernimiento de los televidentes. Entre los que están en el estudio, interviene uno que permite entrever en sus dichos, una relación directa a los discursos de identificación partidario: “(...) Señor Edipo y señora Yocasta, reciban un saludo combatiente y revolucionario de todos los pacientes con esquizofrenia del hospital psiquiátrico de las Erinias, a quienes represento" ${ }^{18}$.

Una de las llamadas efectuadas al programa es la realizada por Orestes, quien juzga a Edipo y al programa mismo:

(...) Me parece el colmo, que programas serios y paradigmáticos como el suyo, Licenciada Gorgona, se preste para la exhibición de ese par de desvergonzados.

\footnotetext{
${ }^{15}$ Geirola 2010: 501.

${ }^{16}$ Geirola 2010: 502.

${ }^{17}$ Geirola 2010: 502.

${ }^{18}$ Geirola 2010: 508.
} 
Porque que alguien mate a su madre se entiende, y hasta se agradece, pero que alguien se case con ella es de un mal gusto que resiente las columnas de nuestra cultura helénica.

Gorgona - ¿Quién habla?

PARricida - Orestes, hijo y asesino de mamita Clitemnestra ${ }^{19}$.

Este personaje mitológico, se introduce en la obra para juzgar. Si se enciende el televisor en este mismo momento, se encuentra a personas opinando, juzgando, construyendo teorizaciones sobre temas ajenos, simple y sencillamente por un minuto de aire.

A partir de este programa, Yocasta se pregunta qué pasaría si ellos fueran personas corrientes, sin fama. Esta estrategia de escritura, que se repetirá durante la obra, da pie al siguiente acto: "Un matrimonio corriente" en la cual hay un cambio de roles: Edipo cocina, mientras Yocasta mira un partido de fútbol. Cuando discuten, el marido va a quejarse de su esposa con su madre. Allí se produce la típica escena hijo-nuera-suegra, digna de cualquier telenovela.

La publicidad, es otro de los discursos que se destacan: "Edipo: Ahora solo somos unos reyes-esposos que suelen ir al supermercado a comprar polvo de ángeles. / Yocasta: Recomendado por Edipo y su señora mamacita, para todos los incestuosos del reino" ${ }^{20}$. O este spot que nos remite a otro internacionalmente conocido: "La imagen es nada, Freud, es todo"

Claro que el médico austríaco no podía estar ausente. Tiene un lugar importante en la obra. Es otro de los productos de la televisión, un programa de preguntas y repuestas, presentado de la siguiente manera por el Coro: "Este es el Oráculo de Tebas. Pase usted a la rueda de la fortuna de su subconsciente y gánese un futuro sin culpas. Con ustedes, el conductor del oráculo, el Doctor Sigmund Freud y nuestro primer concursante, el señor Edipo"22. En forma intercalada, mientras Edipo responde los requerimientos del Freud, y en relación directa con sus respuestas, Yocasta canta fragmentos de canciones populares. Todas ellas tienen como temática "la madre", es posible identificar piezas de Leo Dan, Los Chalchaleros, José López, entre otros.

El Rey gana y obtiene un destino sin culpas. Edipo agradece: “(...) al oráculo y a mi destino, que me han permitido ser el único hombre que a pesar de llamarse Edipo no goza del complejo que lleva su nombre"23. Lo ha logrado, podrá estar tranquilo desafiando al destino.

\footnotetext{
${ }^{19}$ Geirola 2010: 507.

${ }^{20}$ Geirola 2010: 511.

${ }^{21}$ Geirola 2010: 511.

${ }^{22}$ Geirola 2010: 511.

${ }^{23}$ Geirola 2010: 512.
} 
Pero este festejo dura muy poco. Creonte, desde un helicóptero, le recuerda que quien tiene el poder sobre el destino es Zeus. Por ello el próximo acto es un partido de ajedrez. Retrotrayendo al espectador a la idea de que los hombres son solo piezas de ajedrez que Dios mueve.

Nadie puede ganarle a Zeus, el Edipo de Sófocles lo sabe: “(...) no hay hombre que capaz fuera de forzar a los dioses en algo que no quieran" 24 . Pero el personaje de Andino Moscoso, se atreve a interpelar al dios: “(...) ¿Por qué no ordenas que el pueblo tome la jeringuilla y me reviente los ojos, por qué no dejas que construyan un cadalso y ejecuten a Yocasta? ¿Por qué no dejas que cumplan con su papel de verdugos?" 25 . A lo que el dios responde: "Cuando los reyes se hacen daño, el sistema continúa; cuando el pueblo les hace daño, el sistema se acaba. No quiero una revolución sino un cambio de piezas para continuar con el juego" ${ }^{26}$. No se va a aceptar una revolución, sino un cambio, el pueblo no puede intervenir, eso sería un daño irreparable al sistema político. Zeus gana la partida, Jaque Mate a los reyes, deben cumplir sus destinos: Edipo se arranca los ojos, Yocasta se coloca la banda presidencial.

El último acto, es una parodia de una Cadena Nacional. Yocasta, le habla al pueblo:

(...) Hijos de Tebas, hijos de Edipo ahora podrán sacar a sus madres de las cajas mortuorias en que las ponen para adorarlas los segundos domingos de mayo, y podrán sentarlas en los altares de los manicomios para culparlas de sus miserias como lo hicieron conmigo, como lo harán con sus hijas, como lo hacen con sus esposas. Hijas de Tebas, hijas de Yocasta, ahora podrán parir esposos que las golpeen porque no son sus madres, ahora podrán casarse con hijos que las abandonen porque no son sus esposas. Ahora podrán ser lo que siempre fueron: mujeres y hombres tristes. Nada cambiará, ahora es ayer, y el ayer siempre será pecado en este reino ${ }^{27}$.

Al finalizar su discurso, la reina se pone la banda en el cuello.

Al comenzar la obra, Edipo le pregunta a Yocasta: “ $¿ E n$ verdad estamos en Tebas?”28 y ella responde afirmativamente. Pero, en esta última etapa de la representación, durante la cadena nacional Yocasta realiza un acertijo: “¿Cuál es el nombre de un reino de 275.000 kilómetros cuadrados, en donde nadie se atreve a decir que el rey está desnudo?“ ${ }^{29}$. La respuesta ya no será Tebas sino

\footnotetext{
${ }^{24}$ S., O. T. $280-281$.

${ }^{25}$ Geirola 2010: 513.

${ }^{26}$ Geirola 2010: 513-514.

${ }^{27}$ Geirola 2010: 514-515.

${ }^{28}$ Geirola 2010: 504.

${ }^{29}$ Geirola 2010: 515.
} 
Ecuador. El coro lo confirma en el último enunciado de la obra: "Tebas querida, Ecuador del alma" ${ }^{30}$.

El público confirma que todo ha sido una metáfora. No solamente se ha parodiado e ironizado sobre el discurso televisivo, sino que también se ha estado haciendo mención a su país. A un “(...) Ecuador culposo y abusivo, un país de gobernantes travestidos y de hijos alimentados con sangre" ${ }^{31}$. La obra está relacionada con uno de los hechos políticos más trascendentales de finales del siglo pasado, la destitución del presidente Abdalá Bucaram (n. 1952), en 1997. La misma fue realizada por el Congreso argumentando "incapacidad mental" a pocos meses de haber asumido su mandato. Bucarám, se autodenominaba el "superhéroe de los pobres", y se caracterizó por un gobierno de carácter populista y extravagante. Días después de su destitución, al igual que Edipo, debe dejar su patria, se exilia en Panamá, y culpa a la oligarquía de su país por haber planificado su destitución.

Esta no es una interpretación forzada, Edipo rey y su señora mamacita está dedicada "Al loco incomprendido de Panamá" ${ }^{2}$. Y si se revisa los actos de este gobernante, encontramos coincidencias con la obra: Bucarám, por ejemplo, nombra a su familia en diversos cargos políticos, no es ocioso, entonces, que sea Edipo la obra elegida para representarlo. Según Ortíz de Zárate “(...) los mítines de quien se ufanaba de portar un apodo popular, tan insólito en un gobernante, como El Loco terminaban invariablemente en un desenfrenado espectáculo de canto y baile, a veces con él mismo actuando sobre la tarima (...)”33, incluso editó un disco que tituló "Un loco que ama" que llegó a regalar a los presidentes de la región en una Cumbre Iberoamericana. Quizás por esto, en la obra de Andino Moscoso, Yocasta dice que al finalizar el mandato de Edipo, los hombres y las mujeres volverán a estar tristes.

En Edipo rey y su señora mamacita, los diputados reparten estimulantes al pueblo, y "Mientras los sentidos de los tebanos se confunden, los políticos se aprovechan para convocar a elecciones y aprobar amnistías para los ladrones y asesinos" ${ }^{34}$. Amnistías de las que en Ecuador gozó Bucarám antes de ser presidente, por delitos de corrupción.

Los dichos de campaña de este mandatario ecuatoriano fueron extravagantes, baste como ejemplo el siguiente: "Con Abdalá nos hundimos o nos salvamos, pero no seguiremos como estamos" ${ }_{35}$, que no dista mucho de los parlamentos de los personajes de la obra que se viene analizando.

\footnotetext{
${ }^{30}$ Geirola 2010: 515.

${ }^{31}$ Espinosa Andrade 2010: 497.

${ }^{32}$ Geirola 2010: 501.

${ }^{33} \mathrm{~S} / \mathrm{d}$.

${ }^{34}$ Geirola 2010: 510.

35 Ortiz de Zárate s/d.
} 
Para ir finalizando, se puede decir que luego de este recorrido se han podido ver las relaciones interdiscursivas e intertextuales que posee la obra de Andino Moscoso y cómo estas van mucho más allá de una simple alusión a la obra de Sófocles, a los medios masivos de comunicación o a la política de su país. Parodia e ironiza, pero también generaliza. Bucarám/Edipo no es, ni será el único "Loco" que gobierne un país, con simplemente revisar la historia latinoamericana, es posible realizar una larga lista de acciones extravagantes de locos gobernantes.

La influencia nociva de la televisión se da en cada rincón del mundo y lo que esta obra pretende mostrar es la idiotización del público, la mediatización de todo lo que le sucede al ser humano. La pretensión falsa de construir un público con vos propia, que no es tal, por el simple hecho de ser calificado como idiota.

En la obra de Sófocles Edipo dice que no se puede ir contra los designios de los dioses, en la de Andino Moscoso, es posible concluir que no hay hombre que pueda torcer el designio de la influencia nociva de los medios de comunicación. La televisión genera que todo sea un gran circo y hoy, casi 20 años después del estreno de la obra, podemos constatar que nada escapa al loco ojo de la mediatización. 


\section{Bibliografía}

Andino Moscoso, P. (2010), "Edipo rey y su señora mamacita (presidente que se casó con su madre)", in Proaño Gomez, L., Geirola, G. (eds.), Antología del teatro latinoamericano. Tomo 2. Buenos Aires, Inteatro: 501-515.

Angenot, M. (1984), Interdiscursividades. De hegemonías y disidencias. Córdoba, Editorial Universidad Nacional de Córdoba.

Espinosa Andrade, A. (2010), "Peky Andino Moscoso", in Proaño Gomez, L., Geirola, G. (eds.), Antología del teatro latinoamericano. Tomo 2. Buenos Aires, Inteatro: 495-498.

Genette, G. (1989), Palimpsestos. La literatura en segundo grado. Madrid: Taurus. Graves, R. (1985). Los mitos griegos. 2. Buenos Aires, Alianza Editorial: 2010.

Hartwig, S., Pörtl, K. (eds.) (2008), "Peky Andino Moscoso", in La voz de los dramaturgos: El teatro español y latinoamericano actual. Disponible en: $\quad$ http://books.google.com.ar/books?id=k168P-bNiksC\&pg=PA9 $1 \& \mathrm{dq}=$ peky+andino + moscoso \&hl=es\&sa $=\mathrm{X} \& \mathrm{ei}=\mathrm{XebFUYrbH7O}-$ 4AOR7YCQDw\&ved=0CCwQ6AEwAA

Kristeva, J. (1969), “La palabra, el diálogo y la novela”, in Semiótica 1. (1981) Madrid, Fundamentos: 187-225.

Sófocles (2004), Edipo Rey. Buenos Aires: Terramar.

\section{Páginas de Internet}

Ortiz de Zárate, Roberto. "Abdalá Bucaram Ortiz”, en

http://www.cidob.org/es/documentacio/biografias_lideres_politicos/america_ del_sur/ecuador/abdala_bucaram_ortiz. Consultado 15 de julio de 2013. 